group are among our most useful remedies. This opinion I have often heard expressed also by physicians practicing in Carlsbad, Kissingen, Homburg and other European resorts where the waters are of this type.

I have used the French Lick waters in all of the cases here reported and, after making due allowance for such favorable extraneous influences as resorts of this character afford, I am confident that much benefit has. been obtained from their use.

I have not, however, even in the cases in which constipation was most obstinate, prescribed the water in large quantities nor have I relied wholly on the drinking of the water but have employed it locally as well. The greatest benefit to be derived from its use is, I believe, in its influence on secretion, and for this purpose large quantities are not advisable. Warm enemas of olive oil are often of the greatest service in the cure of the attendant constipation: Tonic baths, conjoined with local and general massage, have been largely used both for their effect on the circulation and the relief of intestinal atony. Warm fomentations over the abdomen are very grateful if there is much pain or tenderness.

The indications for abdominal massage are much the same as for the coarser forms of diet. It should never be employed when it produces pain. In many cases I have found that vibratory massage acted even better than when manually performed.

Exercises, particularly such as bring into use the abdominal muscles, are most beneficial in promoting peristalsis, and in fact outdoor exercises generally, provided they are not carried to the point of undue fatigue, serve an excellent purpose. The greater the diversion and interest they afford, the better will be the results obtained.

There are few conditions in which the psychical element enters more largely into causation than it does in colitis, and we are justified, I think, in availing ourselves. of the same influence in treatment; in some cases its importance is to be placed before that of any other measure. Optimism on the part of the physician and his ability to obtain the confidence of the patient count for much in the relief of mental depression, a common feature of these cases, and like influences are to be obtained from change of scene and cheerful surroundings.

\section{SURGICAL TREATMENT}

As regards the operations of appendicostomy and cecostomy recently exploited with some enthusiasm by certain surgeons in the treatment of colitis, chronic constipation and other intestinal conditions hitherto regarded as within the scope of medical art, I can only say that $I$ believe it is possible to reach any part of the colon by lavage through the rectum and the advantages to be gained in providing an artificial opening through which to apply local treatments are more than offset by the depressing effect of the operation and the presence of a fistulous tract which must later be closed. As Richardson has recently observed:

Operations on the neurasthenic return nothing to the patient. Her last state is worse than her first and is often pitiable. The best rule is to forbid surgery until every medical and palliative measure has.proved useless.

\section{PROGNOSIS}

The prognosis is, as a rule, favorable, although improvement is often tedious. It is impossible to give any statistical data on this point regarding the cases here referred to, as most of them have been lost sight of after leaving the springs. The immediate results have been most gratifying, and in a large proportion of those cases in which I have been able to follow the subsequent history, the improvement has been of a more or less permanent character. A considerable number have been cured.

\section{A CASE OF EXTENSIVE LEUKEMIC INFIL- TRATION OF THE MAMMARY GLAND AND SKIN *}

\author{
CHRISTIAN DENCKER, M.D. \\ CHICAgO
}

This case is reported because it exhibits, some rare features, as lymphatic infiltration of the lips, nose and pinna, and a most remarkable involvement of the mammary glands, which I have been unable to find described in the literature.

History.-Mrs. S., Austrian, aged 47, came to the Rush medical clinic complaining of shortness of breath, hoarseness, swollen lips and nose, and pain on swallowing. There was nothing of any moment in the family history. The patient had always enjoyed good health, and had had four children; no miscarriages. Her teeth, however, had been in a bad condition for years without receiving proper care. Her present trouble began about nine months before she came to the clinic with redness and itching of the nose, which was soon followed by swelling of the nose and lips. During this time she had been treated by various physicians for "cold" and eczema, and in the course of the treatment all her teeth were extracted.

Examination.-The patient was a medium-sized woman, fairly well nourished, skin clear; there was no jaundice or abnormal pigmentation. The lower eyelids were edematous; the pupils reacted to light and accommodation, and were rather contracted; the eye muscles worked well. The retinæ showed spots of a grayish exudate; the margins of both disks were somewhat indistinct and striated on the nasal side, but the sight was not appreciably impaired. There was no exophthalmos.

The nose appeared symmetrically enlarged, reddish in color, firm and indurated on palpation. Breathing through the nose with mouth closed was difficult and brought out a marked stridor.

The lips were considerably swollen, the upper somewhat more than the lower one; the mucosa was tense and shiny, the tissue hard and indurated. The patient complained frequently of a severe burning and itching sensation of the lips and to a less degree of the nose. The oral eavity was without teeth; the gum margins were ulcerated and bleeding, the palate was abnormally arched, and posteriorly there was a diffuse swelling which extended on both sides into the pharynx. Tonsils, palate and postpharyngeal wall, all seemed involved in this swelling. The voice was very hoarse or whispering. The dyspnea was at times associated with distinct stridor and marked inspiratory descent of the trachea. Periodically there appeared a violent, brassy cough.

The pinna of the right ear was enlarged to almost double its normal size and was of a reddish color, the tissue being firm and infiltrated. The left pinna was normal. Both drums were retracted and opaque in color. The hearing power was not diminished to an appreciable extent.

All superficial lymph-glands of the body were enlarged to a various extent. The least enlargement was in the glands of the neck, especially in those of the posterior triangle, although even these were easily palpable. There was no fusion of the glands and no fixation of the overlying skin. The largest superficial glands were those of the axillæ.

The mammæ appeared symmetrically enlarged, firm and infiltrated. The glands were somewhat movable; the skin over them was tense, shiny, but not fixed; the nipples were not

* From the Medical Clinic of Rush Medical College and the Department of Pathology of the University of Chicago. 
retracted. No separate nodules could be felt in the glands. No connection between the mammæ and the large lymph-glands of the axillæ could be made out. The apex-beat was in the fifth space, inside the nipple-line and somewhat heaving. Extension of the heart to the right of the sternum could not be establisled by percussion. There was no thrill. The first sound in the mitral area was loud and short, ending in a distinct murmur. At irregular intervals an extra-systole was thrown in, and later a distinct gallop-rhythm developed. In the pulmonie area there was a rough, grating, systolic murmur, at times distinetly purring, so that pulmonic obstruction was suspected. (At autopsy, however, the valves as well as the aorta and pulmonic artery were found to be normal.)

Percussion note over the right lung was slightly dull, especially over the anterior aspect. Breath sounds were somewhat distinct, more so over the right lung. There were no râles.

The abdomen was full, and in the left hypochondrium a tumor mass was readily felt, which issued from beneath the left costal arch and extended beyond the umbilicus. The tumor was somewhat movable, descended with respiration, was slightly tender, of hard consistency, notched on the median surface. Slight percussion over the tumor brought out a flat note. The lower margin of the liver descended to about 2 inches below the costal arch in the mammary line; its consistency was not much increased; its surface was smooth. No glandular masses could be palpated in the abdomen. The umbilicus was freely movable and not retracted.

At the time of admission to the clinic a skin tumor as large as a small walnut was noticed in the posterior axillary line of the right side. This tumor disappeared later. The deep reflexes were normal.

The blood-count showed 110,000 white cells, 82 per cent. small and 6 per cent. large lymphocytes, and a moderate secondary anemia.

Transient skin-rashes (areas of hyperemia) were observed at different times.

The urine contained traces of albumin and a few casts; gravity 1.020 .

Course of Disease.-The patient was under observation about three weeks. During this time the dyspnea was increasing and caused much discomfort to the patient. Tracheotomy was considered, but the general condition of the patient seemed to exclude such an operation. Venesection gave temporary relief. Toward the end there was marked cardiac insufficiency with gallop-rhythm, very irregular pulse and pulmonary edema.

According to the statement of the patient the disease began with redness and itching of the skin of the nose, that was soon followed by swelling of the nose and lips. She was treated for months for eczema by various physicians, and it seems likely that at this time the general swelling of the lymph-glands was not apparent. It is therefore reasonable to assume that the skin lesion was the earliest manifestation of the disease.

The most remarkable feature in this case was found in the condition of the mammary gland, a condition which I have failed to find described in the literature, although in a very few cases lymphomata have been reported in the lacrimal, parotid and maxillary glands in association with lymphomata outside the glands. ${ }^{1}$

An autopsy was performed by Dr. H. Gideon Wells, and the histologic study of the tissues was made by Dr. B. F. Davis, and an abstract of their report follows:

There were found the usual lymphatic hyperplasias of chronic lymphatic leukemia, lymphoid infiltration of the viscera, and in addition lymphoid infiltration of the skin

1. Pinkus: Ueber die Hautveränderungen bei lymphatischer 1. Pinkus: Ueber die Hautverinderungen bei lymphatischer
Leukämle und Pseudo-Leukämie, Arch. f. Dermat. u. Syph., 1899 , I, Nos. 1, 2 .

Nos. 1, 2. Ergänzungsheft.

Kaposi : Pathologie und Therapie der Hautkrankheiten, Vlenna.

Kreibich : Eln Fall von leukämischen Tumoren der Haut, Arch. f Dermat. u. Syph., 1899, xlvii, 185 .

Kümmel : Mitt a. d. Grenzgeb. d. Med. u. Chir., 1897, ii, 111. of the nose and lips. The mammary glands were found replaced by a mass of lymphoid tissue of uniform consistence, resembling in its gross appearances sarcomatous tissue, the mass of new tissue when dissected away from the skin and adjacent fat tissue from one breast measuring 12 by 12 by 4 $\mathrm{cm}$. , and weighing $350 \mathrm{gm}$. Microscopically the normal tissue of the mammary gland was found to have disappeared almost entirely, the remains of an isolated gland tubule or duct being found only rarely in the mass of large and small round cells which make up the growth. These cells infiltrate the connective tissues in the nipple and areolæ up to, but not into the epithelium, accounting for the swollen condition of the areolæ. (A full report of the anatomic findings will be published in the Transactions of the Chicago Pathological Society.)

\section{A NEW STAIN FOR BACTERIAL CAPSULES WITH SPECIAL REFERENCE TO PNEUMOCOCCI *}

\section{E. C. ROSENOW, M.D.}

After much experimentation the following method for staining bacterial capsules has been devised. It has proved of such value in a study of autolysis of pneumococci, in their identification in culture and exudates as well as in staining the capsule of Streptococcus mucosus and, with a slight modification, the capsule of the Bacillus mucosus also, that a brief report seems desirable at this time.

\section{DIRECTIONS}

Make a thin smear on a perfectly clean slide or cover-glass. If the material, such as sputum, is too thick, add enough distilled water so that it can be spread evenly by means of a piece of fine tissue or cigarette paper. In case of cultures (blood-agar, serum, glucose or Loeffler's blood-serum being preferable), remove a small amount of the growth from the surface of the medium and at once mix thoroughly with a loopful of serum on the slide, or, better still, make a rather dense suspension in a few drops of distilled water and then mix an equal quantity of this suspension with serum, and spread by means of tissue-paper. As the smear becomes nearly dry cover for ten to twenty seconds with 5 to 10 per cent. aqueous solution of tannic acid; wash in water and blot; stain with carbol [saturated alcoholic solution gentian violet (Grübler) 1 pt., 5 per cent. phenol in water, 4 pts.] or anilin gentian violet, half a minute to a minute, heat over flame but do not boil; wash in water again; Gram's iodin solution for half a minute to a minute; decolorize in alcohol (95 per cent.); stain for from two to ten seconds, depending on the thickness of smears, with saturated alcoholic ( 60 per cent.) solution of Grubler's eosin; wash in water and blot finally, clear in xylol and mount in balsam, or examine directly. (If the organism, like the Bacillus mucosus, ' is Gram-negative, the bacillus may be stained with Loeffler's or aqueous methylene blue.)

The pneumococci are stained deeply brownish black, sharply differentiated from the capsule, which is stained pink. Beautiful results are also obtained with the Streptococcus mucosus. In the thickest part of the smear the space occupied by the capsule may be perfectly clear; elsewhere in the smear, if properly made, where the conditions are suitable for absorption of eosin, the capsule is stained deeply pink; not rarely a clear retraction zone (often mistaken for the capsule in former methods) may be seen peripherally to a distinctly stained, often large capsule.

In case of sputum in which the cocci are embedded in a more or less tenacious mucus the capsules, at times, are not rendered stainable by the above method. In. that case it is well to fix and stain simultaneously with the 2 per cent. aqueous tannic acid, 4 parts, and saturated solution of gentian

* From the Memorial Institute for Infectious Diseases. For a more complete report see Jour. Infect. Dis., 1911, viil. 